\title{
Obstructive sleep apnea and multimorbidity
}

\author{
Laurence Robichaud-Hallé ${ }^{\prime}$ Michel Beaudry ${ }^{2}$ and Martin Fortin $2,3^{*}$
}

\begin{abstract}
Background: Obstructive sleep apnea (OSA) is becoming increasingly prevalent in North America and has been described in association with specific chronic diseases, particularly cardiovascular diseases. In primary care, where the prevalence of co-occurring chronic conditions is very high, the potential association with OSA is unknown. The purpose of this study was to explore the association between OSA and 1) the presence and severity of multimorbidity (multiple co-occurring chronic conditions), and 2) subcategories of multimorbidity.

Methods: A cluster sampling technique was used to recruit 120 patients presenting with OSA of various severities from the records of a sleep laboratory in 2008. Severity of OSA was based on the results of the polysomnography. Patients invited to participate received a mail questionnaire including questions on sociodemographic characteristics and the Disease Burden Morbidity Assessment (DBMA). They also consented to give access to their medical records. The DBMA was used to provide an overall multimorbidity score and sub-score of diseases affecting various systems.

Results: Bivariate analysis did not demonstrate an association between OSA and multimorbidity $(r=0.117$; $p=0.205)$. However, severe OSA was associated with multimorbidity (adjusted odds ratio $=7.33$ [1.67-32.23], $p=0.05)$. OSA was moderately correlated with vascular $(r=0.26, p=0.01)$ and metabolic syndrome $(r=0.26, p=0.01)$ multimorbidity sub-scores.

Conclusions: This study showed that severe OSA is associated with severe multimorbidity and sub-scores of multimorbidity. These results do not allow any causal inference. More research is required to confirm these associations. However, primary care providers should be aware of these potential associations and investigate OSA when deemed appropriate.
\end{abstract}

Keywords: Obstructive sleep apnea, Multimorbidity, Disease Burden Morbidity Assessment, Chronic disease, Severity

\section{Background}

Millions of North Americans are affected by the consequences of sleep disorders. Among these disorders, sleep apnea syndrome has the highest rate of mortality and morbidity [1]. According to the Public Health Agency of Canada, 858,900 Canadians reported suffering from sleep apnea, and almost $26 \%$ of Canadians are at high risk of developing the condition [2]. This disorder poses a major public health problem due to its prevalence, severity and socioeconomic burden. Obstructive sleep apnea (OSA) is defined as the cessation of naso-buccal air flow for more than 10 seconds [3], and is diagnosed

\footnotetext{
* Correspondence: Martin.Fortin@USherbrooke.ca

${ }^{2}$ Centre de santé et de services sociaux de Chicoutimi, Saguenay, Québec, Canada

${ }^{3}$ Département de médecine de famille, Université de Sherbrooke, 305, St-Vallier, Chicoutimi, Québec G7H 5H6, Canada

Full list of author information is available at the end of the article
}

based on an apnea-hypopnea index (AHI) value greater than five per hour of sleep [4], usually accompanied by a $4 \%$ decrease in oxygen saturation [4]. It is estimated that $80 \%$ of obstructive sleep apnea cases remain undiagnosed [5], making it difficult to identify patients at risk of associated comorbidities [6]. Reuveni et al. suggest that programs be developed to increase the level of suspicion of OSA among primary care providers [7].

OSA syndrome is independently associated with an increased risk of mortality $[8,9]$. Fletcher [10] reported that $70 \%$ to $90 \%$ of patients with OSA have hypertension [10]. Associations between OSA and heart failure [11], OSA and arrhythmias [12], OSA and diabetes [13], OSA and insulin resistance [14] and OSA and metabolic syndrome [15] have also been reported. Successful treatment of OSA helps to better control many of the associated diseases and chronic conditions [11,16-18]. Men, people 40 years old and over, and those with a high

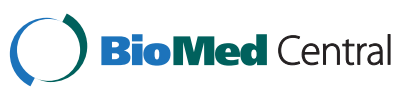

(c) 2012 Robichaud-Hallé et al.; licensee BioMed Central Ltd. This is an Open Access article distributed under the terms of the Creative Commons Attribution License (http://creativecommons.org/licenses/by/2.0), which permits unrestricted use, distribution, and reproduction in any medium, provided the original work is properly cited. 
body mass index (BMI) or a large neck circumference are at greater risk for OSA [19-21].

Multimorbidity - the co-occurrence of two or more chronic diseases-is an emerging concept in the medical literature [22]. One study showed that nine out of ten primary care patients had more than one chronic condition, while approximately $50 \%$ had five or more [23]. Multimorbidity has been associated with several adverse effects, such as a reduction in quality of life [24,25], an increase in psychological distress [26], medical complications and increased mortality [27].

Evidence of an association between OSA and multimorbidity could be an important incentive for the systematic screening for OSA in primary care settingswhere the prevalence of multimorbidity is very high. The first objective of this study was to measure the association between the severity of OSA and the severity of multimorbidity, and second, to explore the association between OSA and various categories of multimorbidity.

\section{Methods}

This study used data from the sleep laboratory of the Centre de santé et de services sociaux de Chicoutimi (CSSSC), a regional health centre in the Saguenay region of Québec (Canada). As a first step in the recruitment process, a list of patients who had undergone polysomnography in 2008 was compiled. Patients were categorized according to the severity of their OSA, based on their polysomnography results (absent: AHI 0-4; mild: AHI 5-14; moderate: AHI 15-29; severe: $\mathrm{AHI} \geq 30$ ). We selected consecutive patients from each category to ensure a proportional representation (25\% each) of the four OSA categories. French-speaking patients were selected between 30 and 75 years of age, to ensure adequate variation in degrees of multimorbidity. Each patient underwent polysomnography after January 1, 2008, either in the sleep laboratory as a full night or a split-night study: the first half of the night is used to obtain a diagnosis, the second half is used to perform continuous positive airway pressure (CPAP) titration (level I), or, at home as an outpatient (level II). Patients with a diagnosis of upper airway resistance were excluded from the study, as were people who slept less than three hours a night and those referred for a diagnosis other than apnea, such as parasomnia.

After providing informed consent, participants selected at this stage received a questionnaire covering multimorbidity and socio-demographic variables. Data related to variables of the evaluation conducted at the sleep laboratory were recorded: age, sex, polysomnography results, neck circumference, weight and height.

Several tools are available for measuring multimorbidity. The Disease Burden Morbidity Assessment (DBMA) was selected for this study as it allows to report the absence or presence of 21 predetermined chronic conditions and additional chronic conditions and to determine a functional impact score for each condition on daily life activities [28]. The DBMA is a self-report questionnaire. For each condition present, the patient assesses a degree to which the condition limits his or her activities on a five-point descriptive scale (1: Not at all - 5: A lot). The total score is made up of the sum of all limitations. The metrological qualities and validity of this instrument have been described by Bayliss et al. [28] and a French version was validated in a recent study: sensitivity $73.9 \%$ (62.5\%-90\%); specificity $92.2 \%$ (77.6\%98.6\%) [29]. The questionnaire was sent by mail based on a modified Dillman method [30]. A second questionnaire was sent to non-respondents 30 days following the first one. Estimated time to complete the questionnaire is approximately 15 minutes.

Due to the exploratory nature of the study, we based our sample size estimation on the availability of the data and feasibility. We aimed for a sample size of 120 (30 per OSA group) to ensure a good representation of each category of the independent variable. We oversampled for a potential non response of 30 to $40 \%$. Consequently, the questionnaire was sent to a convenience sample, as recommended by Dillman [31], of 194 people who had undergone polysomnography at the sleep laboratory of the CSSSC for a diagnosis of sleep apnea in 2008. The study received ethics approval from the Research Ethics Board of the CSSSC.

The subject's characteristics were described using medians (in the case of asymmetric distributions), means, standard deviations (for continuous variables) and proportions (for categorical variables). A KolmogorovSmirnoff test was performed to test for normality of the distributions. In the absence of normality, non-parametric tests were conducted. Bivariate (Spearman rank) correlations were conducted. We dichotomized the AHI by grouping together absent and mild as well as moderate and severe to ensure sufficient size of each group. We performed logistic regression analyses to study the relationship between multimorbidity and OSA. The significance level was set at 0.05 , and confidence intervals were calculated at 95\%. The DBMA constituted the dependent variable and OSA classification, the independent variable. Other variables were included in the models as adjustment variables (BMI, sociodemographic variables). Neck circumference was not included, as $25 \%$ of the data was missing. We dichotomized the DBMA using the median and threshold values of 10 and 20, respectively, to explore the association with clinical variables. Cut-off points were chosen based on the definition of multimorbidity and the results of previous studies [23,32]. A score of 10 means a high impact and at least two chronic conditions; a score of 20 represents a very high impact and at least four 
chronic conditions (considered here as severe multimorbidity). DBMA sub-groups were formed on the basis of the correlation of each disease with OSA and the conceptual association. We tested three sub-groups: vascular DBMA (hypertension, heart disease, dyslipidemia, heart failure and stroke); cardio DBMA (hypertension, heart disease, dyslipidemia, heart failure) and metabolic syndrome DBMA (hypertension, cholesterol, obesity and diabetes). Data were analyzed using the SPSS package (19.0, SPSS, Chicago. IL).

\section{Results}

Of the 194 patients solicited, seven were non-eligible: five were suffering from parasomnia, one was too old and one we were unable to reach to complete the questionnaire. In total, 187 eligible patients were invited to participate and 120 completed the questionnaire $(64.2 \%$ response rate). No patients were excluded. Among these, $89.2 \%$ of participants had OSA. The average age of patients was 55.5 years, with a predominance of males (65\%).

Table 1 presents the characteristics of the 120 patients. The average neck circumference (absent: $41.17 \mathrm{~cm}$; mild: $40.5 \mathrm{~cm}$; moderate: $42.59 \mathrm{~cm}$; severe: $43.99 \mathrm{~cm}$ ) and BMI average (absent: 32.00; mild: 30.13; moderate: 34.39; severe: 35.77$)$ were higher in moderate and severe OSA.

The 120 respondents presented six chronic diseases in average. The average number of diseases did not increase in accordance with the severity of OSA (absent: seven diseases; mild: five diseases; moderate: eight diseases; severe: five diseases). Table 2 (DMBA results) shows the distribution of diseases in the sample. The following conditions were present in $50 \%$ or more of the patients: obesity (80.8\%), hypertension (52.5\%) and dyslipidemia (50\%).

Table 3 reveals an association between polysomnography results (absent + mild vs. moderate + severe) and BMI $(r=0.261, p=0.01)$ and gender $(r=0.244, p=0.01)$ and a similar trend with neck circumference $(r=0.265$, $p=0.05)$, and with income $(\mathrm{r}=0.218, p=0.05)$. We were unable to demonstrate a statistically significant association between the DBMA score and dichotomized polysomnography (absent + mild vs. moderate + severe) $(\mathrm{r}=0.117, p=\mathrm{NS})$ in this analysis. With regard to multimorbidity sub-scores, Table 3 shows weak correlations between sleep apnea and vascular DBMA and between OSA and metabolic syndrome DBMA. None of the sociodemographic variables were associated with OSA.

Tables 4 and 5 show a significant association between severity of DBMA and severe OSA. There was also a significant association between DBMA and severe OSA (an AHI over 30). This association was not observed in patients with mild to moderate OSA. None of the subscores presented in Table 3 showed an association with severity of OSA in logistic regression analyses (results not shown).

\section{Discussion}

The present study revealed an association between severe OSA and severity of multimorbidity as measured by the DBMA. The relationship was still present after adjusting for several potential confounders.

These findings have implications for general practice. Many patients seen in primary care practices present with multimorbidity. In order to investigate the potential association between multimorbidity and OSA, screening could be done clinically or by using a tool such as the Epworth Instrument which is highly correlated with OSA [33]. Patients could be referred to a sleep lab for evaluation when OSA is suspected. If OSA is confirmed, it may affect the management of the patient who could benefit from treatment that has been demonstrated to help control many associated diseases and chronic conditions [11,16-18].

One previous study suggests that multimorbidity exists in OSA [34]. To our knowledge, this is the first study to report an association between severe OSA and multimorbidity. We searched for an exposure-response

Table 1 Patient characteristics

\begin{tabular}{|c|c|c|c|c|c|}
\hline \multirow[t]{3}{*}{ Variable } & \multicolumn{4}{|c|}{ AHI } & \multirow[t]{3}{*}{ Total } \\
\hline & Absent & Mild & Moderate & Severe & \\
\hline & $(0-4)$ & $(5-14)$ & $(15-29)$ & $\overline{(30 \text { and over) }}$ & \\
\hline Polysomnography results (\%) & $13(10.8)$ & $23(19.2)$ & $36(30.0)$ & $48(40.0)$ & \\
\hline Neck circumference * & $41.17 \pm 4.98$ & $40.49 \pm 4.12$ & $42.59 \pm 5.23$ & $43.99 \pm 3.61$ & $42.28 \pm 5.63$ \\
\hline Mean \pm standard deviation (min and max) & $(34.7-50.5)$ & $(31.0-47.0)$ & $(32.0-59.9)$ & $(37.0-51.5)$ & $(31.0-59.9)$ \\
\hline Body mass index & $32.0 \pm 6.7$ & $30.1 \pm 6.7$ & $34.4 \pm 7.2$ & $35.8 \pm 7.7$ & $33.9 \pm 7.4$ \\
\hline Mean \pm standard deviation (min and max) & $(22-47)$ & $(18-42)$ & $(24-60)$ & $(21-65)$ & $(18-65)$ \\
\hline DBMA & $16.0 \pm 11.1$ & $14.5 \pm 9.6$ & $21.2 \pm 11.4$ & $15.3 \pm 11.8$ & $16.9 \pm 11.5$ \\
\hline Mean \pm standard deviation (min and max) & $(2-36)$ & $(0-40)$ & $(2-40)$ & $(1-55)$ & $(0-55)$ \\
\hline Mean number of diseases & 7 diseases & 5 diseases & 8 diseases & 5 diseases & 6 diseases \\
\hline
\end{tabular}

$* \mathrm{~N}=90$. 
Table 2 DBMA results

\begin{tabular}{|c|c|c|c|c|c|}
\hline \multirow[t]{2}{*}{ Disease } & \multicolumn{4}{|c|}{$\mathrm{AHI}$} & \multirow{2}{*}{$\begin{array}{l}\text { Sampling } \\
\text { percentag }\end{array}$} \\
\hline & $0-4$ & $5-14$ & $16-29$ & $(\geq 30)$ & \\
\hline Obesity & $10(8.3 \%)$ & $17(14.2 \%)$ & $31(25.9 \%)$ & $39(32.5 \%)$ & $97(80.8 \%)$ \\
\hline Hypertension & $6(5 \%)$ & $9(7.5 \%)$ & $21(17.5 \%)$ & $27(22.5 \%)$ & $63(52.5 \%)$ \\
\hline Dyslipidemia & $4(3.3 \%)$ & $6(5 \%)$ & $24(20 \%)$ & $26(21.7 \%)$ & $60(50.0 \%)$ \\
\hline Ostheoarthritis & $6(5 \%)$ & $11(9.2 \%)$ & $19(15.8 \%)$ & $15(12.5 \%)$ & $51(42.5 \%)$ \\
\hline Back pain or sciatica & $6(5 \%)$ & $5(4.2 \%)$ & $20(16.7 \%)$ & $20(16.7 \%)$ & $51(42.5 \%)$ \\
\hline Gastrointestinal ulcer & $5(4.2 \%)$ & $11(9.2 \%)$ & 19 (15.8\%) & $12(10 \%)$ & $47(39.2 \%)$ \\
\hline Leg circulation problems & $4(3.3 \%)$ & $7(5.8 \%)$ & $18(15 \%)$ & $15(12.5 \%)$ & $44(36.7 \%)$ \\
\hline Other joint diseases & $5(4.2 \%)$ & $6(5 \%)$ & $15(12.5 \%)$ & $15(12.5 \%)$ & $41(34.2 \%)$ \\
\hline Hearing disorder & $1(0.83 \%)$ & $8(6.7 \%)$ & $11(9.2 \%)$ & $18(15 \%)$ & $38(31.7 \%)$ \\
\hline Depression and anxiety & $7(5.8 \%)$ & $7(5.8 \%)$ & $9(7.5 \%)$ & $12(10 \%)$ & $35(29.2 \%)$ \\
\hline Diabetes & $5(4.2 \%)$ & $3(2.5 \%)$ & $11(9.2 \%)$ & $12(10 \%)$ & $31(25.8 \%)$ \\
\hline Heart disease & $2(1.7 \%)$ & $5(4.2 \%)$ & $9(7.5 \%)$ & $14(11.7 \%)$ & $30(25.0 \%)$ \\
\hline Asthma & $3(2.5 \%)$ & $5(4.2 \%)$ & $13(10.8 \%)$ & $9(7.5 \%)$ & $30(25.0 \%)$ \\
\hline Vision disorder & $1(0.83 \%)$ & $2(1.7 \%)$ & $9(7.5 \%)$ & $7(5.8 \%)$ & $19(15.8 \%)$ \\
\hline Osteoporosis & $2(1.7 \%)$ & $3(2.5 \%)$ & $10(8.3 \%)$ & $3(2.5 \%)$ & $18(15 \%)$ \\
\hline Bowel disease & $1(0.8 \%)$ & $4(3.3 \%)$ & $6(5 \%)$ & $5(4.2 \%)$ & $16(13.3 \%)$ \\
\hline Chronic bronchitis or emphysema & $2(1.7 \%)$ & $2(1.7 \%)$ & $6(5 \%)$ & $5(4.2 \%)$ & $15(12.5 \%)$ \\
\hline Thyroid & $1(0.83 \%)$ & $2(1.7 \%)$ & $4(3.3 \%)$ & $5(4.2 \%)$ & $12(10.0 \%)$ \\
\hline Heart failure & $2(1.7 \%)$ & 0 & $3(2.5 \%)$ & $6(5 \%)$ & $11(9.2 \%)$ \\
\hline Stroke & 0 & $2(1.7 \%)$ & $3(2.5 \%)$ & $5(4.2 \%)$ & $10(8.3 \%)$ \\
\hline Rheumatoid arthritis & 0 & 0 & $3(2.5 \%)$ & $2(1.7 \%)$ & $5(4.2 \%)$ \\
\hline Cancer & 0 & $1(0.8 \%)$ & $2(1.7 \%)$ & $1(0.8 \%)$ & $4(3.3 \%)$ \\
\hline
\end{tabular}

Table 3 Bivariate analysis with dichotomized polysomnography results

\begin{tabular}{|c|c|c|}
\hline Variable & $r^{*}$ & $p$ value \\
\hline BMI & 0.261 & 0.01 \\
\hline Neck circumference & 0.265 & 0.05 \\
\hline Sex & 0.244 & 0.01 \\
\hline Income & 0.218 & 0.05 \\
\hline Vascular DBMA (sub-score) & 0.261 & 0.01 \\
\hline Cardiac DBMA (sub-score) & 0.196 & 0.05 \\
\hline Metabolic syndrome DBMA (sub-score) & 0.261 & 0.01 \\
\hline DBMA score & 0.117 & 0.205 \\
\hline Age & 0.132 & 0.151 \\
\hline Marital status & 0.109 & 0.090 \\
\hline Place of birth & 0.085 & 0.355 \\
\hline Education & -0.026 & 0.780 \\
\hline \multicolumn{3}{|c|}{$\begin{array}{l}\text { Dichotomized polysomnography: } 0=\text { absent + mild; } 1=\text { moderate + severe } \\
\text { DBMA sub-score: Cardiac DBMA: Hypertension, heart disease, dyslipidemia, } \\
\text { heart failure; Vascular DBMA: Hypertension, heart disease, dyslipidemia, heart } \\
\text { failure, stroke; } \\
\text { Metabolic syndrome DBMA: Hypertension, cholesterol, obesity and diabetes } \\
\text { *Spearman correlation. }\end{array}$} \\
\hline
\end{tabular}

relationship between OSA and multimorbidity but the composition of our sample prevented us from observing such a relationship. In our sample we did not obtain the desired proportion representation (25\% each) of the four severity categories of the independent variable (OSA: absent, mild, moderate and severe). We sent the DBMA questionnaire to 50 people in each OSA classification category but we had a disproportionately high response

Table 4 Logistic regressions unadjusted

\begin{tabular}{lccc}
\hline Variable/Result & OR & $\boldsymbol{p}$ value & $\mathbf{9 5 \% ~ C l}$ \\
\hline Median DBMA (14.00) & Mild: 1.31 & 0.670 & $0.38-4.50$ \\
& Moderate: 1.17 & 0.755 & $0.49-3.21$ \\
& Severe: 2.70 & 0.029 & $1.11-6.60$ \\
\hline DBMA 10 & Mild: 1.23 & 0.755 & $0.33-4.61$ \\
& Moderate: 0.85 & 0.761 & $0.31-2.38$ \\
& Severe: 3.40 & 0.031 & $1.15-10.36$ \\
\hline DBMA 20 & Mild: 1.33 & 0.675 & $0.35-5.13$ \\
& Moderate: 0.63 & 0.475 & $0.18-2.23$ \\
& Severe: 3.00 & 0.020 & $1.19-7.56$ \\
\hline
\end{tabular}

Median DBMA: $0=$ DBMA from 0 to 13.99 and $1=14$ and over.

DBMA 10: $0=$ DBMA from 0 to 9.99 and $1=10$ and over.

DBMA 20: $0=$ DBMA from 0 to 19.99 and $1=20$ and over. 
Table 5 Logistic regression analyses adjusted for sex, age, BMI and income

\begin{tabular}{lccc}
\hline Variable/result & OR & $\boldsymbol{p}$ value & $\mathbf{9 5 \% ~ C l}$ \\
\hline Median DBMA (14.00) & Mild: 0.90 & 0.909 & $0.16-5.03$ \\
& Moderate: 0.92 & 0.912 & $0.22-3.84$ \\
& Severe: 3.94 & 0.021 & $1.24-12.59$ \\
\hline DBMA 10 & Mild: 1.41 & 0.696 & $0.25-7.92$ \\
& Moderate: 0.83 & 0.798 & $0.26-3.37$ \\
& Severe: 4.34 & 0.021 & $1.22-15.44$ \\
\hline DBMA 20 & Mild: 1.12 & 0.911 & $0.16-7.75$ \\
& Moderate: 0.32 & 0.229 & $0.05-2.07$ \\
& Severe: 7.33 & 0.008 & $1.67-32.23$ \\
\hline
\end{tabular}

Median DBMA: $0=$ DBMA from 0 to 13.99 and $1=14$ and over.

DBMA 10: $0=$ DBMA from 0 to 9.99 and $1=10$ and over.

DBMA 20: $0=$ DBMA from 0 to 19.99 and $1=20$ and over.

rate in the severe category (48 out of the 50 patients) compared to the others. On the other hand, we obtained a sample of relatively sicker subjects (an average DBMA of 16). Patients in this study presented more chronic conditions (six per person) than reported by Fortin [23] (4.6 per person) or Kadam (1.3 per person) [32] in their assessment of multimorbidity in primary care practices. We suspect that the disproportionate response rate is due to the fact that patients who were sicker were more interested in participating in this study.

Regarding other characteristics and associations, the respondents were fairly representative of the sleep apnea population, with a predominance of male subjects [21]. Neck circumference and BMI were found to be positively associated with OSA, which was expected [21]. We observed an association between the AHI and metabolic syndrome. This association had been previously found by other groups [35,36]. Although not addressed in our study, associations were also found between OSA and each component of the metabolic syndrome. In fact, the evidence suggests that OSA is actually part of the metabolic syndrome. One study suggests that OSA symptoms (snoring, hyper somnolence) predict the development of metabolic syndrome. In addition, evaluation of OSA symptoms can help identify individuals who are at risk of developing metabolic syndrome [35].

Our sleep laboratory uses a definition of hypopnea which is accepted in the literature: a decrease in respiratory amplitude of $50 \%$ or more, accompanied by a desaturation of $3 \%$ [37]. However, other laboratories require a $4 \%$ desaturation for a positive diagnosis. The method used in this study is therefore more sensitive than the diagnostic criteria used in some laboratories. This could result in higher AHI values and the number of diagnoses of patients with mild or moderate symptoms who would not have been diagnosed by other laboratories. Several epidemiological studies have established a relationship between OSA and vascular morbidity using the $4 \%$ cutoff point [38]. This may explain why we did not observe any link between our groups of mild or moderate subjects and a measure of morbidity. It is especially important that studies showing a link between sleep apnea and morbidity examine these associations, particularly in the case of severe OSA (AHI greater than 30). Also, if OSA is an intermediate factor in the development of hypertension, diabetes, dyslipidemia or other conditions, controlling for these variables represents a case of "over adjustment," potentially affecting the association between dependent and independent variables $[39,40]$.

For more than 20 years, cross-sectional studies, control cases and other evidence have suggested an association between OSA and heart disease, heart failure, arrhythmias and cerebrovascular diseases [8,9,12,40]. A gradation of vascular risk in relation to $\mathrm{AHI}$ has been proposed [40]. We observed an association between vascular DBMA and AHI when AHI was dichotomized into absent and mild versus moderate and severe. Similar results were obtained in prospective population studies, such as the Sleep Heart Health Study [41] and the Wisconsin Sleep Cohort Study [42]. In the first study, Gottlieb identified an association between incident heart failure and OSA. Although there is no defined threshold value, this association is especially important in subjects with an AHI greater than 30. In the Wisconsin study, the associations were significant only in subjects with an AHI greater than 30 (odds ratios of 4.5 and 5.2, respectively, for risks of cerebral vascular disease and cardiovascular death). Furthermore, a longitudinal study showed that men are at increased risk of stroke when the AHI is greater than 19 per hour of sleep. Among women, unadjusted overall results showed an increased risk threshold at 25 AHI per hour of sleep $(p=0.002)$ [39].

This study has limitations. With a limited response rate of $64 \%$, we were unable to obtain a proportional representation in categories of OSA classification in our sample, and this may have confounded the relationship between the DBMA and OSA. In addition, we had to remove one variable from the analysis (neck circumference) due to a high number of missing values. Another limitation of the study is the use of the DBMA as a measure of multimorbidity. The DBMA measures self-reported disease burden that correlates well with quality of life outcomes [28]. However, in other multimorbidity measures, disease severity is evaluated based on purely clinical criteria assessed by health professionals. The different methods of evaluating disease severity may have an impact on the association between multimorbidity and OSA.

\section{Conclusions}

In this study we found a link between severe obstructive sleep apnea and severity of multimorbidity. These results 
represent the first documentation of a relationship between severity of OSA and severity of multimorbidity. The study also showed an association between OSA and multimorbidity sub-scores (cardiac, vascular, metabolic syndrome). Primary care providers should be aware of these potential associations and investigate OSA when deemed appropriate. There is a need for additional research in this area, and our findings may help raise awareness among family physicians about this condition and improve access to diagnosis and treatment. Research would benefit from repeating the same study using a longitudinal study design.

\section{Competing interests}

This was not an industry-supported study and the authors have indicated no financial conflict of interest. This research received financial supported from the CIHR Applied Research Chair - Health Services and Policy Research on Chronic Diseases in Primary Care/Canadian Institutes of Health ResearchInstitute of Health Services and Policy Research, Canadian Health Services Research Foundation and Centre de santé et de services sociaux de Chicoutimi.

\section{Authors' contributions}

LRH conceived the study, conducted the data collection, and participated in its design and in the data analysis. $\mathrm{LRH}$ also wrote the manuscript. $\mathrm{MB}$ and MF supervised the first author's work and participated in its design and data analysis. All authors read and approved the final manuscript. LRH takes responsibility for the integrity of the work as a whole.

\section{Acknowledgments}

This study was made possible by the CIHR Applied Research Chair - Health Services and Policy Research on Chronic Diseases in Primary Care/Canadian Institutes of Health Research-Institute of Health Services and Policy Research, Canadian Health Services Research Foundation and Centre de santé et de services sociaux de Chicoutimi. We would like to thank staff members of the sleep laboratory at the CSSSC and Mrs. Diane Lacombe, consultant, for her advice on ensuring the relevance and adequacy of the statistical analysis. We also want to thank Jose Almirall, Susie Bernier and Tarek Bouhali for reviewing and editing this manuscript.

\section{Author details}

${ }^{1}$ Université de Sherbrooke, Québec, Canada. ${ }^{2}$ Centre de santé et de services sociaux de Chicoutimi, Saguenay, Québec, Canada. ${ }^{3}$ Département de médecine de famille, Université de Sherbrooke, 305, St-Vallier, Chicoutimi, Québec G7H 5H6, Canada.

Received: 21 March 2012 Accepted: 20 September 2012

Published: 24 September 2012

\section{References}

1. Elgrably F: Epidemiologic findings on sleep apnea syndrome: their value for diabetics][Article in French]. Journ Annu Diabetol Hotel Dieu 2002, 201-212.

2. Quel est limpact de l'apnée du sommeil sur les Canadiens ?: Enquête sur la santé dans les collectivités canadiennes - Réponse rapide sur l'apnée du sommeil. http://www.phac-aspc.gc.ca/cd-mc/sleepapnea-apneesommeil/ffrr-2009-fra.php.

3. Guilleminault C, Tilkian A, Dement WC: The sleep apnea syndromes. Annu Rev Med 1976, 27:465-484.

4. Anonymous: Sleep-related breathing disorders in adults: recommendations for syndrome definition and measurement techniques in clinical research: The Report of an American Academy of Sleep Medicine Task Force. Sleep 1999, 22:667-689.

5. Young T, Evans L, Finn L, Palta M: Estimation of the clinically diagnosed proportion of sleep apnea syndrome in middle-aged men and women. Sleep 1997, 20:705-706.

6. Piccirillo JF, Duntley S, Schotland H: Obstructive sleep apnea. JAMA 2000, 284:1492-1494.
7. Reuveni H, Tarasiuk A, Wainstock T, Ziy A, Elhayany A, Tal A: Awareness level of obstructive sleep apnea syndrome during routine unstructured interviews of a standardized patient by primary care physicians. Sleep 2004, 27:1518-1525.

8. Marshall NS, Wong KK, Liu PY, Cullen SR, Knuiman MW, Grunstein RR: Sleep apnea as an independent risk factor for all-cause mortality: the Busselton Health Study. Sleep 2008, 31:1079-1085.

9. Young T, Finn L, Peppard PE, Szklo-Coxe M, Austin D, Nieto FJ, Stubbs R, Hla KM: Sleep disordered breathing and mortality: eighteen-year follow-up of the Wisconsin sleep cohort. Sleep 2008, 31:1071-1078.

10. Fletcher EC: Cardiovascular consequences of obstructive sleep apnea: experimental hypoxia and sympathetic activity. Sleep 2000, 23(Suppl 4):S127-S131.

11. Wolf J, Lewicka J, Narkiewicz K: Obstructive sleep apnea: an update on mechanisms and cardiovascular consequences. Nutr Metab Cardiovasc Dis 2007, 17:233-240.

12. Roche F, Xuong AN, Court-Fortune I, Costes F, Pichot V, Duverney D, Vergnon JM, Gaspoz JM, Barthelemy JC: Relationship among the severity of sleep apnea syndrome, cardiac arrhythmias, and autonomic imbalance. Pacing Clin Electrophysiol 2003, 26:669-677.

13. Reichmuth KJ, Austin D, Skatrud JB, Young T: Association of sleep apnea and type II diabetes: a population-based study. Am J Respir Crit Care Med 2005, 172:1590-1595.

14. Ip MS, Lam B, Ng MM, Lam WK, Tsang KW, Lam KS: Obstructive sleep apnea is independently associated with insulin resistance. Am J Respir Crit Care Med 2002, 165:670-676.

15. Nieto FJ, Peppard PE, Young TB: Sleep disordered breathing and metabolic syndrome. WMJ 2009, 108:263-265.

16. Strohl KP: Diabetes and sleep apnea. Sleep 1996, 19(10 Suppl):S225-S228.

17. Young T, Peppard PE, Gottlieb DJ: Epidemiology of obstructive sleep apnea: a population health perspective. Am J Respir Crit Care Med 2002, 165:1217-1239.

18. Lavie P, Lavie L: Cardiovascular morbidity and mortality in obstructive sleep apnea. Curr Pharm Des 2008, 14:3466-3473.

19. Young T, Palta M, Dempsey J, Skatrud J, Weber S, Badr S: The occurrence of sleep-disordered breathing among middle-aged adults. N Engl J Med 1993, 328:1230-1235.

20. À propos de l'apnée du sommeil: qu'est ce que c'est? http://www.poumon. ca/diseases-maladies/apnea-apnee/what-quoi/index_f.php.

21. Young T, Skatrud J, Peppard PE: Risk factors for obstructive sleep apnea in adults. JAMA 2004, 291:2013-2016.

22. van den Akker M, Buntinx F, Knottnerus JA: Comorbidity or multimorbidity: what's in a name? A review of literature. Eur J Gen Pract 1996, 2:65-70.

23. Fortin M, Bravo G, Hudon C, Vanasse A, Lapointe L: Prevalence of multimorbidity among adults seen in family practice. Ann Fam Med 2005, 3:223-228.

24. Fortin M, Lapointe L, Hudon C, Ntetu AL, Maltais D, Vanasse A: Multimorbidity and quality of life in primary care: A systematic review. Health Qual Life Outcomes 2004, 2:51.

25. Fortin M, Bravo G, Hudon C, Lapointe L, Almirall J, Dubois MF, Vanasse A: Relationship between multimorbidity and health-related quality of life of patients in primary care. Qual Life Res 2006, 15:83-91.

26. Fortin M, Bravo G, Hudon C, Lapointe L, Dubois MF, Almirall J: Relationship between psychological distress and multimorbidity of patients in family practice. Ann Fam Med 2006, 4:417-422.

27. Fortin M, Soubhi H, Hudon C, Bayliss EA, van den Akker M: Multimorbidity's many challenges. BMJ 2007, 334:1016-1017.

28. Bayliss EA, Ellis JL, Steiner JF: Subjective assessments of comorbidity correlate with quality of life health outcomes: Initial validation of a comorbidity assessment instrument. Health Qual Life Outcomes 2005, 3:51

29. Poitras M-E, Fortin M, Hudon C, Haggerty J, Almirall J: Validation of the disease burden morbidity assessment by self-report in a Frenchspeaking population. BMC Health Service Research 2012, 12:35.

30. Dillman DA: Mail and Telephone Surveys: The Total Design Method. New York: John Wiley and Sons; 1978.

31. Dillman DA: Mail and Internet Surveys. The tailored design method. 2nd edition. New York: John Wiley \& Sons, Inc; 2000.

32. Kadam UT, Croft PR, North Staffordshire G. P. Consortium Group: Clinical multimorbidity and physical function in older adults: a record and 
health status linkage study in general practice. Fam Pract 2007, 24:412-419.

33. Rosenthal LD, Dolan DC: The Epworth sleepiness scale in the identification of obstructive sleep apnea. J Nerv Ment Dis 2008, 175(7):408-18. 196:429-431.

34. Smith R, Ronald J, Delaive K, Walld R, Manfreda J, Kryger M: What are obstructive sleep apnea patients being treated for prior to this diagnosis? Chest 2002, 121:164-172.

35. Nock NL, Li L, Larkin EK, Patel SR, Redline S: Empirical evidence for "syndrome Z": a hierarchical 5-factor model of the metabolic syndrome incorporating sleep disturbance measures. Sleep 2009, 32:615-622.

36. Troxel WM, Buysse DJ, Matthews KA, Kip KE, Strollo PJ, Hall M, Drumheller O, Reis SE: Sleep symptoms predict the development of the metabolic syndrome. Sleep 2010, 33:1633-1640.

37. Iber C: American Academy of Sleep Medicine: The AASM manual for the scoring of sleep and associated events: rules, terminology and technical specifications. Westchester, IL: American Academy of Sleep Medicine; 2007.

38. Ruehland WR, Rochford PD, O'Donoghue FJ, Pierce RJ, Singh P, Thornton AT: The new AASM criteria for scoring hypopneas: impact on the apnea hypopnea index. Sleep 2009, 32:150-157.

39. Redline S, Yenokyan G, Gottlieb DJ, Shahar E, O'Connor GT, Resnick HE, Diener-West M, Sanders MH, Wolf PA, Geraghty EM, et al: Obstructive sleep apnea-hypopnea and incident stroke: the sleep heart health study. Am J Respir Crit Care Med 2010, 182:269-277.

40. Young T, Peppard P: Sleep-disordered breathing and cardiovascular disease: epidemiologic evidence for a relationship. Sleep 2000, 23(Suppl 4):S122-S126

41. Gottlieb DJ, Yenokyan G, Newman AB, O'Connor GT, Punjabi NM, Quan SF, Redline S, Resnick HE, Tong EK, Diener-West M, Shahar E: Prospective study of obstructive sleep apnea and incident coronary heart disease and heart failure: the sleep heart health study. Circulation 2010, 122:352-360.

42. Young T, Palta M, Dempsey J, Peppard PE, Nieto FJ, Hla KM: Burden of sleep apnea: rationale, design, and major findings of the Wisconsin Sleep Cohort study. WMJ 2009, 108:246-249.

doi:10.1186/1471-2466-12-60

Cite this article as: Robichaud-Hallé et al:: Obstructive sleep apnea and multimorbidity. BMC Pulmonary Medicine 2012 12:60.

\section{Submit your next manuscript to BioMed Central and take full advantage of:}

- Convenient online submission

- Thorough peer review

- No space constraints or color figure charges

- Immediate publication on acceptance

- Inclusion in PubMed, CAS, Scopus and Google Scholar

- Research which is freely available for redistribution 